\title{
Ultrasound in Rheumatoid Arthritis
}

\section{Chiara Rizzo, Fulvia Ceccarelli, Angelica Gattamelata, Caterina Vavala, Guido Valesini, Annamaria Iagnocco}

Rheumatology Unit, Dipartimento di Medicina Interna e Specialità Mediche, Sapienza Università di Roma, Rome, Italy

\begin{abstract}
Rheumatoid arthritis (RA) is a chronic inflammatory disease characterized by synovial inflammation that can lead to structural damage of cartilage, bone and tendons. Assessing the inflammatory activity and the severity is essential in RA to help rheumatologists in adopting proper therapeutic strategies and in evaluating disease outcome and response to treatment. In the last years musculoskeletal (MS) ultrasonography (US) underwent tremendous technological development of equipment with increased sensitivity in detecting a wide set of joint and soft tissues abnormalities. In RA MSUS with the use of Doppler modalities is a useful imaging tool to depict inflammatory abnormalities (i.e. synovitis, tenosynovitis and bursitis) and structural changes (i.e. bone erosions, cartilage damage and tendon lesions). In addition, MSUS has been demonstrated to be able to monitor the response to different therapies in RA to guide local diagnostic and therapeutic procedures such as biopsy, fluid aspirations and injections. Future applications based on the development of new tools may improve the role of MSUS in RA.

Keywords: rheumatoid arthritis, ultrasound, synovitis, erosions, power Doppler
\end{abstract}

\section{Introduction}

Rheumatoid arthritis (RA) is a multifactorial, chronic, systemic, inflammatory disease affecting primarily the joints [1]. The disease affects approximately $0.5-1 \%$ of population and leads into progressive joint destruction responsible of disability, restriction of daily living and deterioration of quality of life [2]. The need of an early suppression of inflammatory process, to prevent the bone erosive damage, determined the introduction, in the daily clinical practice, of new imaging modalities to identify signs of disease activity in early phases [3].

Musculoskeletal (MS) ultrasound (US) has been widely employed in the assessment and monitoring of

Received 25.05.2013 Accepted 05.06.2013

Med Ultrason

2013, Vol. 15, No 3, 199-208

Corresponding author: Annamaria Iagnocco, Dipartimento Medicina Interna e Specialità Mediche: Reumatologia, Sapienza Università di Roma, V.le del Policlinico 155, Rome - 00161, Italy Tel: +3906 49974634, Fax: +390649974642 Email: annamaria.iagnocco@uniroma1.it rheumatic diseases, particularly in patients affected by RA. Thanks to its characteristic of validity, reliability reproducibility and sensitivity to change, US superseded other commonly used imaging modalities, such as plain radiography (X-ray), and its use has been included in the daily routine clinical practice in rheumatology [4].

US technique includes the use of gray scale (GS) imaging and Doppler modalities. GS images the anatomic structures and Doppler shows blood flow. Their use is indicated for the evaluation of peri- and intra-articular structures, providing an accurate depiction of soft tissue and bony cortex changes at all stages of the disease [4] (fig 1, fig 2).

The standardisation of the technique is a relevant aspect for US. In 2001 the EULAR guidelines indicated the standard scans to perform at each joint for the evaluation of articular and peri-articular structures [5]. In 2005, the OMERACT group published consensus US definitions for common pathologic lesions observed in patients affected by RA [6]. According with the OMERACT indications, synovial fluid was defined as an abnormal hypoechoic or anechoic intra-articular material that is displaceable and compressible, and that does not exhibit 

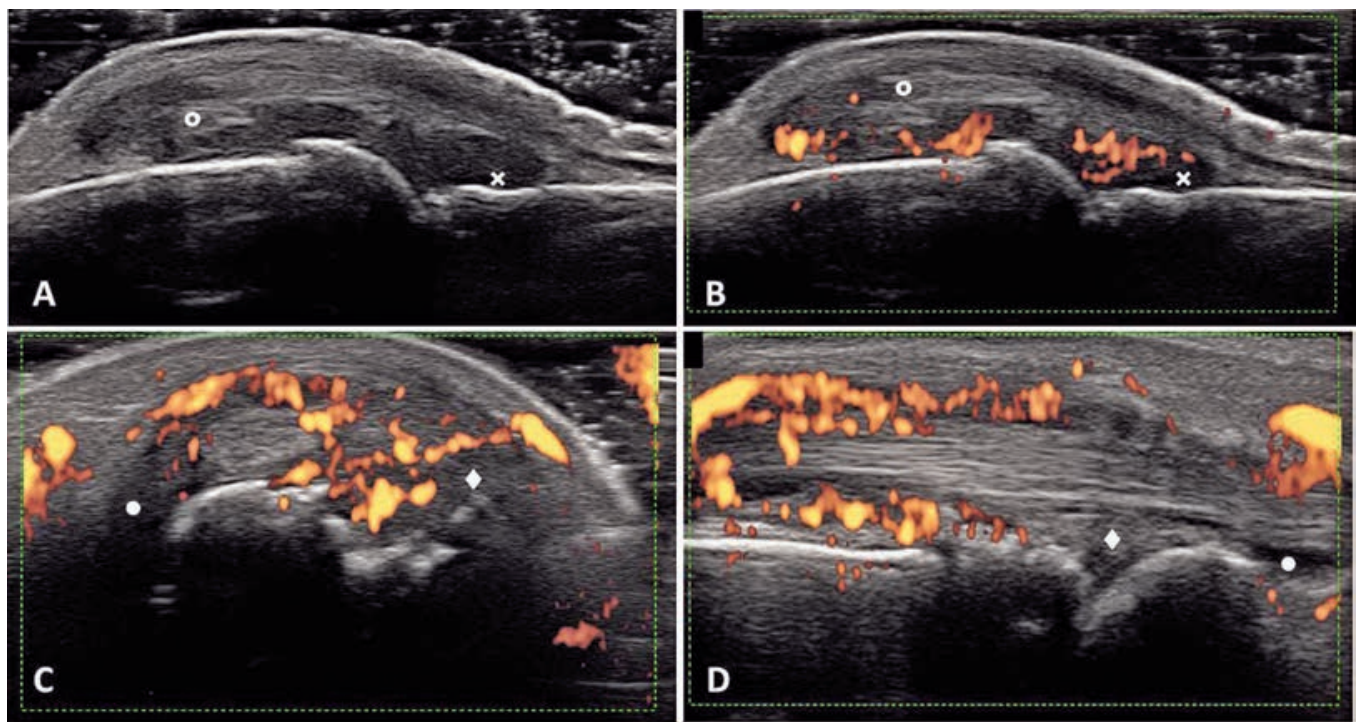

Fig 1. Grey-scale and PD US of the hand and wrist in rheumatoid arthritis patients. A: Dorsal longitudinal scan of the 2nd metacarpophalangeal joint showing signs of synovitis on B-mode modality; B: Dorsal longitudinal scan of the 2nd metacarpophalangeal joint showing signs of active synovitis with local hypervascularization on power Doppler modality; C,D: Transverse (C) and longitudinal (D) scans of extensor carpi ulnaris tendon showing signs of tenosynovitis on power Doppler modality. $\mathbf{x}$ : joint effusion; $\mathbf{0}$ : synovial hypertrophy; $\bullet$ : effusion within the tendon sheath; $\diamond$ : synovial hypertrophy within the tendon sheath.

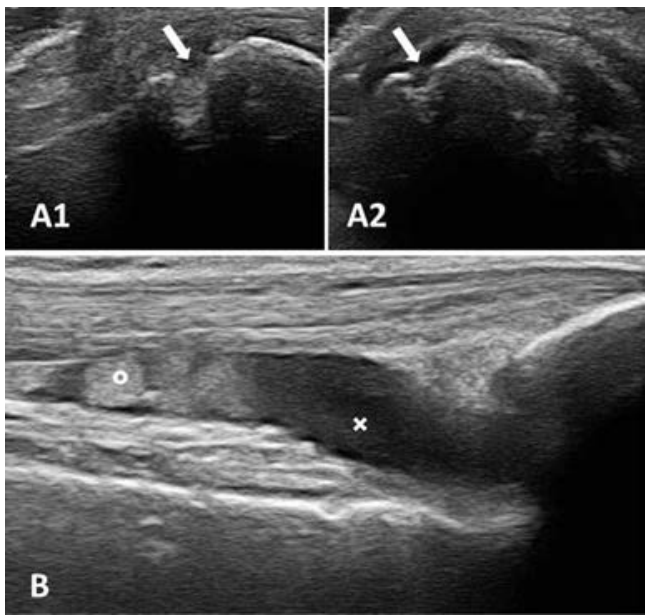

Fig 2. Gray-scale US in rheumatoid arthritis patients. A1, A2: Dorsal longitudinal (A1) and transverse (A2) scan of the right ulnar epiphysis showing the presence of bone erosions (arrows); B: Suprapatellar longitudinal scan of the left knee showing signs of synovitis. $\mathbf{x}$ : joint effusion; o: synovial hypertrophy.

Doppler signal; synovial hypertrophy as an abnormal hypoechoic intra-articular tissue that is non-displaceable and poorly compressible and that may exhibit Doppler signal; tenosynovitis as hypoechoic or anechoic thick- ened tissue with or without fluid within the tendon sheath that is seen in 2 perpendicular planes, and that may exhibit Doppler signal; finally, bone erosion as an intraarticular discontinuity of the bone surface that is visible in 2 perpendicular planes [6]. US can be usefully applied in the assessment and monitoring of patients affected by RA. Several studies demonstrated a great sensitivity of US in the detection of signs of inflammation compared with the clinical assessment and in the evaluation of bone erosive damage, compared with X-ray [4,7-9].

\section{Inflammatory changes}

\section{a) Synovitis}

Synovitis is a key feature of RA. An inflammatory status at joint level is characterized by the presence of synovial effusion and/or hypertrophy and by the increase of local vascularization. In the presence of synovial hypertrophy, the application of power Doppler (PD) and color Doppler (CD) techniques can help in differentiating between active and inactive inflammation [10]. The term of synovitis is used to indicate the presence of synovial hypertrophy with PD signal and joint effusion. Changes in PD reflect modifications of disease activity, and the presence of PD has been associated with development of erosions [11].

The OMERACT Task Force suggested the application of a standardized scoring system, combining GS and PD, 
based on consensus definitions and standardized acquisition protocol $[12,13]$. Semiquantitative scoring systems have been developed, to assess the changes over time: the most commonly used ranges from 0 to 3 , according to the severity of the alteration, being $0=$ absent, $1=$ mild, $2=$ moderate, $3=$ severe. This score is usually calculated for each variable analysed (synovial fluid, synovial hypertrophy, Doppler signal) and has been applied in the monitoring of response to treatment, with encouraging results. Recent published studies evaluated the sensitivity to change of PDUS in the evaluation of the response to biological drugs, showing a significant reduction of joint inflammation, as evaluated by GS or PD assessment, and significant correlations with disease activity indices, such as the Disease Activity Score (DAS28) [14-18].

However, there is lack of consensus concerning which target joints should be assessed, and which scoring system should be adopted [19]. The perspective to develop a global US score is very interesting, because of the possibility to objectively identify the real level of the inflammatory status at joint level, corresponding to disease activity of patients affected by inflammatory arthritis. Several differences in terms of number and composition of joints evaluated have been identified in the studies published until now [19]. The number of joints to evaluate and include into a global US scoring system is a key issue. The proposed number and composition of reduced joint counts were based either on the frequency of involvement [20-22], or the representative value of target joints [23] or the development of logistic regression models [24,25]. Almost all analyzed papers included the evaluation of at least 6 joints, similarly to the score proposed by Perricone et al [25]. The $2^{\text {nd }}$ metacarpophalangeal joints (MCP) and the wrist were included in all composite US scoring systems.

Another important issue concerning the role of US in RA consists of the possibility of identifying subclinical synovitis. It has been demonstrated that US is more sensitive than clinical examination in detecting inflamed joints [26], being subclinical inflammation not an uncommon feature [27].

In RA the presence of sublinical synovitis in symptom-free joints has been highlighted at hand, wrist, knee and foot joints [28-31]. In addition, subclinical synovitis detected by US-PD was shown to be more likely to progress to structural damage as bone erosions and joint space narrowing [32-34]. Thus US could be a powerful tool to exactly assess joint abnormalities in order to better classify an apparent clinical remission. The presence of subclinical synovitis can be considered as a sign of possible RA progression that needs to be monitored pro- viding useful information to the rheumatologist to decide for the best treatment option [28].

\section{b) Tenosynovitis}

Tenosynovitis is a common feature in patients affected by RA and the tendons assessment is part of US assessment. According to OMERACT, tenosynovitis is defined as hypoechoic or anechoic thickened tissue with or without fluid within the tendon sheath that is seen in 2 perpendicular planes, and that may exhibit Doppler signal [6]. Filippucci et al showed that the $2^{\text {nd }}$ and $4^{\text {th }}$ finger flexor and the extensor carpi ulnaris tendons were often involved in patients affect by RA [35].

Even for tenosynovitis assessment, a GS and PD semiquantitative scoring system has been proposed, ranging from 0 to $3(0=$ normal, $1=$ mild, $2=$ moderate and $3=$ severe) [36]. As for synovitis, scoring of tenosynovitis could be very important in the assessment and monitoring of RA patients during treatment. Despite that, there is no consensus on how to score or how many tendons should be included in a US scoring system for follow-up. In terms of reliability in detecting inflammatory tendon abnormalities in patients affected by RA, an excellent result has been recently obtained both for GS and PD assessments [37].

\section{c) Bursitis}

The broad spectrum of RA manifestations includes peri-articular soft tissues involvement including synovial bursae. Their inflammation determines important pain worsening the quality of life of RA patients. Thus, a rapid identification of RA related bursitis can be essential to adopt an appropriate therapy [38]. The role of US in detecting bursitis in RA patients has poorly been investigated and has been mainly focused on shoulder and foot disease [39-45]. At shoulder level subdeltoid bursitis can be a cause of pain and functional impairment contributing to the global involvement of shoulder in RA patients; it is estimated that $70 \%$ of RA patients suffer from shoulder pain [39]. In a study published in 2008 painful rheumatoid shoulders were assessed by US-PD in order to detect sites of inflammation [39]. One-hundredfifty-eight painful RA shoulders were examined detecting subdeltoid bursitis in the $35 \%$. Bursitis was highlighted when the maximum diameter of the bursa was more than $2 \mathrm{~mm}$ because of the presence of sonolucent fluid with or without additional echogenic material inside of it. Previous studies reported the presence of US-detected subdeltoid bursitis in $18-69 \%$ of rheumatoid shoulders $[41,42]$. Moreover these researches have described the presence of isolated subdeltoid bursitis in RA patients without glenohumoral synovitis confirming that this specific inflammatory alteration can be the exclusive cause of shoulder pain [41]. 
Another important anatomic site that can be characterized by bursitis is the foot [43]. In particular the presence of forefoot bursae in RA patients has been recently studied $[44,45]$. Bowen et al reported a prevalence of US detectable foot bursae of $92.6 \%$ in RA patients. They also demonstrated that US was superior to clinical examination which identified foot bursitis only in $23.5 \%$ of patients [44]. Same authors in 2010 [46] assessed foot of RA patients at baseline and after 12 months in order to detect forefoot bursae and determine their natural history and clinical significance. US detectable foot bursae were found in $93.3 \%$ of participants at 12 months, this result was substantially stable respect to US findings at baseline. However authors demonstrated a high individual variability. Indeed $45 \%$ of patients presented a regression of one or more bursae, while a similar number had new episodes of foot bursitis identified by US. Foot bursitis can therefore be considered a dynamic process and its identification by US is very important to better focus on treatment, as steroid injection, and preventative foot health [46].

US is a valuable imaging tool to detect bursitis at different articular sites in RA patients [47].

\section{Structural damage}

\section{a) Erosions}

According with the OMERACT US definitions, erosion was defined as an intraarticular discontinuity of the bone surface that is visible in 2 perpendicular planes [6]. It is now established the superiority of US in terms of sensitivity, in the assessment of erosive bone damage, compared with X-Ray [48]. In 1999 Backhaus et al found that this technique can visualize more erosions than $\mathrm{X}$ ray in RA patients [49]. In a study conducted on $100 \mathrm{RA}$ patients, Wakefield documented the capability of US to detect the presence of erosive damage 6.5 times more than X-ray [7]. This evidence was further confirmed when Magnetic Resonance or Computed Tomography were used as the reference method, especially in patients with an early phase of the disease [7,50,51]. Standardized scoring systems to evaluate bone erosive damage by using US assessment, are not available so far. The erosive damage have been categorized according with the number of erosions [52], with the number of joints or quadrants showing erosions, or with the dimension of the erosions $[7,51,53,54]$. Moreover, a semiquantitative scoring system, ranging from 0 to 3 according with the number of erosions was suggested by Lopez-Ben et al [55]. The reliability of US in the assessment of erosive damage seems good, as demonstrated by several studies. Particularly, Wakefield and colleagues demonstrated an intra and inter-observer $\mathrm{K}$ value of 0.75 and 0.76 respectively in a cohort of RA patients [7]. More recently, Bajai obtained better results, demonstrating a $\mathrm{K}$ value of 0.98 in the inter-observer evaluation [52].

\section{b) Cartilage}

By using X-ray only indirect signs of cartilage damage can be demonstrated. On the contrary, US assessment could provide detailed imaging of the hyaline cartilage, identifying small cartilage abnormalities in patients affected by RA [56]. US evaluation allows a reliable and valid measurement of cartilage at finger joints level, with great sensitivity compared to X-ray [57]. A good interobserver reproducibility was identified in a study analysing the qualitative morphological modifications of the cartilage at MCP joint level in patients affected by RA [58]. Further evaluations on larger population are needed to better standardize the scoring to assess cartilage damage in RA.

\section{c) Tendon rupture}

Tendon involvement is a common feature in RA. Recurrent episodes of tenosynovitis associated with proliferation of the tenosynovium can lead to tendon structural changes as tendon adhesion and rupture causing severe articular impairment [59]. Even if US has been indicated as the reference imaging technique to evaluate tendons [60] up to date the majority of studies concerning US assessment in RA have focused on the detection of joint inflammation and bone erosions less than on tendon pathology [61-63]. A recent systematic review by Alcalde et al analysed the role of US in assessing tendon lesion in RA and other inflammatory joint disease. The authors pointed out the lack of common agreed definitions to score tendon abnormalities and in particular the absence of clear distinction between partial and compete tendon tear that was applied only in few of the studies reviewed (36). Five studies aimed to identify, beside tenosynovitis, tendon rupture [62,64-67]. Four studies were case series and 1 was a cohort study. Tendon assessed included wrist extensors, hand flexors, ankle tendons and shoulder rotator cuff tendons. Not all researches provided US definition of tendon lesions, adopting a binary quantification system to describe the presence of tendon structural damages, underlining the need for further investigation to propose common scoring systems [36]. Filippucci et al in 2012 published an ultrasonographic study specifically concerning hand tendon involvement in RA [35]. Ninety patients were enrolled assessing hand flexors and wrist extensors. Tendon damage was defined as the presence of tendon echostructure derangement, evidenced as the loss of homogeneity in tendon fibrillar structure due to edema, partial tear and complete rupture, identified when a focal discontinuity or the complete loss of substance was visualized with the 
US beam exactly perpendicular to the tendon to avoid anisotropy $[61,68]$. Tendon damage was found in at least 1 anatomic site in $43.3 \%$ of patients assessed. Particularly, among the 5400 tendons assessed, echostructure derangement, partial tear and complete rupture were retrieved in $5.4 \%, 3.3 \%$ and $0.6 \%$ of RA tendons, respectively [35]. At wrist level, the tendons most frequently involved resulted to be the $1^{\text {st }}$ and $6^{\text {th }}$ compartment extensor tendons. In particular the extensor carpi ulnaris tendon presented more frequently signs of partial tear or complete rupture. This is a well known feature of RA which has in the tendons of the $6^{\text {th }}$ extensor compartment a target of the disease [69]. This study evidenced the utility of US examination in detecting tendon pathology that can easily be misdiagnosed with only clinical examination [61], however concluded that more researches are needed to define the most commonly involved tendon sites to focus US examination on target tendons in RA [35]. In conclusion US can be considered a useful tool to assess tendon damage but more consensus on definitions as well as careful consideration on training and standardization of tendon pathology US assessment is required $[37,67]$.

\section{Main applications}

The main applications of US in the assessment of patients affected by RA include the monitoring of response to treatment and the guide for intra-articular procedures [70]. In the last years, US was widely applied in the assessment of the response to treatment with different drugs, especially in patients treated with biological therapy. The administration of tumor necrosis factor alpha (TNF)-antagonists determines an improvement of synovitis, in terms of PD signal. First, Hau and colleagues observed a significant reduction of the numbers of Doppler signals at MCP level in 5 RA patients [71]. From 2005, when OMERACT definitions were published, 12 studies evaluated the efficacy of anti-TNF drugs by using US assessment [11,16,17,21,24,25,72-77]. The number of patients enrolled in the studies was variable, ranging from 18 to 278 patients. Moreover, a wide variability was identified regarding the therapy assumed by the enrolled patients (etanercept, adalimumab, infliximab) and the follow-up, ranging from 12 weeks and 24 months. The number of joints evaluated was variable: some studies included a single joint (wrist) [75], other studies evaluated a great number of articular sites (78 joints assessed in the study conducted by Hammer et al in 2010) [77]. All studies demonstrated a significant reduction of US score after treatment with TNF-antagonist, irrespective of the follow-up. Moreover, a significant correlation with disease activity indices was identified.
Intra-articular injections of different drugs could be an important approach in the patients with monoarthritis, with a rapid and effective control of inflammatory status. The US guidance resulted in significantly improved results, in terms of performance, increased of responder rate, and increased amount of fluid detected and aspirated $[78,79]$. The most frequently used drugs in patients with RA are corticosteroids. However, different drugs were intra-articular administered in patients with monoarthritis refractory to corticosteroids. US could be used by guide during intra-articular procedure, but also in monitoring the response to treatment. In 2006, Iagnocco et al demonstrated by using US the efficacy of intra-articular administration at the knee level of Methotrexate in 10 patients affected by RA [80]. More recently intra-articular administration of TNF-antagonist infliximab showed encouraging results in the great majority of cases [81].

\section{Additional applications}

The utility of US joint examination has been evidenced in early arthritis patients. Rheumatologists know how important could be making early diagnosis in order to adopt a tight control of disease activity so to modify the natural history of RA. US was demonstrated an important imaging modality to achieve these objectives [82]. Actually US has been shown to be superior to clinical examination in detecting synovitis in early RA $[70,83]$. Such a result suggests that a US count of inflamed joints can be useful to discriminate oligoarthritis from polyarthritis with consequent fundamental prognostic implications [27]. Even to detect bone erosions US was proved more sensitive than X-Rays, depicting them before the evidence on radiograms [7,48,50]. Moreover the presence of high GS score, PD signal and at least one erosion at early stage of disease have been associated with an increased probability of persistent inflammatory arthritis, including RA [84]. Particularly, evidence of erosion at the radial part of $2^{\text {nd }} \mathrm{MCP}$, ulnar part of $5^{\text {th }} \mathrm{MCP}$ and fibular part of $5^{\text {th }}$ metatarsophalangeal joint (MTP) are typical of RA [85]. So their detection seems important in order to adopt the most appropriate therapeutic management of patients. US examination performed at early stage of disease can also help clinicians in making a correct differential diagnosis, in fact the presence of enthesal pathology, especially at sub-clinical level, can lead more easily to a diagnosis of spondyloarthropaty [86]. On the other hand early signs of inflammation of extensor carpi ulnaris have a high predictive value for the development of erosive damage in RA [69]. Furthermore joint US in early arthritis can be useful to properly define clinical remission. US was demonstrated to identify sub-clinical inflammation in patients 
considered in remission and the presence of positive PD signal presented an increased risk of relapse and progression of disease [87]. This stresses that US assessment may be important to classify patients in order to better decide on their treatment. Further studies are needed to define the role of US in the prediction of RA in patients with very early synovitis even if it has been demonstrated to be a useful tool especially when GS and PD scanning were performed on MCP, wrist and MTP joints [88]

Finally, is important to underline the role of US in assessing articular and peri-articular inflammation in juvenile arthritis. US, even in children, has demonstrated higher sensitivity in detecting synovial inflammation and structural damages than clinical examination (89). Moreover US is a rapid, cheap and bedside imaging modality well accepted by young patient that does not require anaesthesiological support, as with magnetic resonance, and does not use radiations which can badly affect children's tissues [89].

\section{Future perspectives}

Several future perspectives concern the US in the evaluation of patients affected by RA. First, new technologies, as 3-dimensional technique and fusion imaging, have been applied in pilot studies, showing higher reliability compared with two-dimensional methods $[90,91]$. Moreover, the use of contrast-enhanced US seems to provide significantly higher sensitivity than PD-US in the identification of abnormal vascularization in joint inflammation, allowing a more exact measurement of the synovitis, as well as a quantitative assessment of inflammation by using the analysis of time-intensity curves. However, its place and benefits in management of RA patients is not yet clearly established and larger studies are needed to better clarify this issue [92].

More recently, few studies have analysed the correlation between synovitis, assessed by using US technique, and biomarkers. Hammer et al evaluated the correlation between the soluble biomarker calprotectin and synovitis, showing significant results: calprotectin was associated with the sum scores from a comprehensive US assessment and was responsive to change during anti-TNF treatment [93]. In 2011, we demonstrated that TGF- $\beta$ 869C/T single nucleotide polymorphism could influence the boneerosive damage as evaluated by US, with a dichotomic behaviour according with the autoantibody status [94].

\section{Conclusions}

US is an imaging method that has recently entered in the clinical practice of rheumatologists as a comple- mentary tool to the clinical assessment of RA. It allows an improvement of the quality of diagnostic and treatment decisions. The higher sensitivity of US examination in the detection of erosive bone damage in RA patients, compared with X-ray is now known, especially in the early stages of the disease. In the current state, a unique scoring system optimal for follow-up the inflammatory status in RA patients is not available, but several researches are addressed to identify a feasible and reliable system, able to replace clinical or composite scores.

Finally, several interesting future perspectives, regarding new techniques and the correlations with biomarkers, should be applied in the researches. However, the possible use in the clinical practice of these new perspectives should be verified.

\section{Conflict of interest: none}

\section{References}

1. Dieudé P, Cornélis F. Genetic basis of rheumatoid arthritis. Joint Bone Spine 2005; 72: 520-526.

2. Lipsky PE. Harrison's Principles of Internal Medicine. In: Isselbacher KJ, Braunwald E, Fauci AS et al. Rheumatoid arthritis. 17th ed. New York, NY: McGraw-Hill; 1994: 1648-1655.

3. Filippucci E, Iagnocco A, Meenagh G, et al. Ultrasound imaging for the rheumatologist II. Ultrasonography of the hand and wrist. Clin Exp Rheumatol 2006; 24: 118-122.

4. Iagnocco A, Ceccarelli F, Perricone C, Valesini G. The role of ultrasound in rheumatology. Semin Ultrasound CT MR 2011; 32: 66-73.

5. Backhaus M, Burmester GR, Gerber T, et al. Guidelines for musculoskeletal ultrasound in rheumatology. Ann Rheum Dis 2001; 60: 641-649.

6. Wakefield RJ, Balint PV, Szkudlarek M, et al. Musculoskeletal ultrasound including definitions for ultrasonographic pathology. J Rheumatol 2005; 32: 2485-2487.

7. Wakefield RJ, Gibbon WW, Conaghan PG, et al. The value of sonography in the detection of bone erosions in patients with rheumatoid arthritis: a comparison with conventional radiography. Arthritis Rheum 2000; 43: 2762-2770.

8. Le Boedec M, Jousse-Joulin S, Ferlet JF, et al. Factors influencing concordance between clinical and ultrasound findings in rheumatoid arthritis. J Rheumatol 2013; 40: 244-252.

9. Di Geso L, Filippucci E, Riente L, et al. Ultrasound imaging for the rheumatologist XL. Sonographic assessment of the hip in rheumatoid arthritis patients. Clin Exp Rheumatol 2012; 30: 464-468.

10. Iagnocco A, Epis O, Delle Sedie A, et al. Ultrasound imaging for the rheumatologist XVII. Role of colour Doppler and power Doppler. Clin Exp Rheumatol 2008; 26: 759762 . 
11. Naredo E, Möller I, Cruz A, Carmona L, Garrido J. Power Doppler ultrasonographic monitoring of response to antitumor necrosis factor therapy in patients with rheumatoid arthritis. Arthritis Rheum 2008; 58: 2248-2256.

12. Wakefield RJ, D'Agostino MA, Iagnocco A, et al. The OMERACT Ultrasound Group: status of current activities and research directions. J Rheumatol 2007; 34: 848-851.

13. D'Agostino MA, Conaghan PG, Naredo E, et al. The OMERACT ultrasound task force Advances and priorities. J Rheumatol 2009; 36: 1829-1832.

14. Ohrndorf S, Backhaus M. Advances in sonographic scoring of rheumatoid arthritis. Ann Rheum Dis 2013; 72: 69-75.

15. Shio K, Homma F, Kanno Y, et al. Doppler sonographic comparative study on usefulness of synovial vascularity between knee and metacarpophalangeal joints for evaluation of articular inflammation in patients with rheumatoid arthritis treated by infliximab. Mod Rheumatol 2006; 16: 220-225.

16. Wakefield RJ, D'Agostino MA, Naredo E, et al. After treatto-target: can a targeted ultrasound initiative improve RA outcomes? Postgrad Med J 2012; 88: 482-486.

17. Iagnocco A, Filippucci E, Perella C, et al. Clinical and ultrasonographic monitoring of response to adalimumab treatment in rheumatoid arthritis. J Rheumatol 2008; 35: 35-40.

18. Filippucci E, Farina A, Carotti M, Salaffi F, Grassi W. Grey scale and power Doppler sonographic changes induced by intra-articular steroid injection treatment. Ann Rheum Dis 2004; 63: 740-743.

19. Mandl P, Naredo E, Wakefield RJ, Conaghan PG, D'Agostino MA; OMERACT Ultrasound Task Force. A systematic literature review analysis of ultrasound joint count and scoring systems to assess synovitis in rheumatoid arthritis according to the OMERACT filter. J Rheumatol 2011; 38: 2055-2062.

20. Qvistgaard E, Røgind H, Torp-Pedersen S, Terslev L, Danneskiold-Samsøe B, Bliddal H. Quantitative ultrasonography in rheumatoid arthritis: evaluation of inflammation by Doppler technique. Ann Rheum Dis 2001; 60: 690-693.

21. Backhaus M, Ohrndorf S, Kellner H, et al. Evaluation of a novel 7-joint ultrasound score in daily rheumatologic practice: a pilot project. Arthritis Rheum 2009; 61: 1194-1201.

22. Hameed B, Pilcher J, Heron C, Kiely PD. The relation between composite ultrasound measures and the DAS28 score, its components and acute phase markers in adult RA. Rheumatology 2008; 47: 476-480.

23. Sheane BJ, Beddy P, O'Connor M, Miller S, Cunnane G. Targeted ultrasound of the fifth metatarsophalangeal joint in an early inflammatory arthritis cohort. Arthritis Rheum 2009; 61: 1004-1008.

24. Naredo E, Rodríguez M, Campos C, et al. Validity, reproducibility, and responsiveness of a twelve-joint simplified power Doppler ultrasonographic assessment of joint inflammation in rheumatoid arthritis. Arthritis Rheum 2008; 59: $515-522$.

25. Perricone C, Ceccarelli F, Modesti M, et al. The 6-joint ultrasonographic assessment: a valid, sensitive-to-change and feasible method for evaluating joint inflammation in RA. Rheumatology 2012; 51: 866-873.

26. Bresnihan B, Kane D. Sonography and subclinical synovitis. Ann Rheum Dis 2004; 63: 333-334.

27. Wakefield RJ, Green MJ, Marzo-Ortego H, et al. Should oligoarthritis be reclassified? Ultrasound reveals high prevalence of subclinical disease. Ann Rheum Dis 2004; 63: $382-385$

28. Ogishima H, Tsuboi H, Umeda N, et al. Analysis of subclinical synovitis detected by ultrasonography and low-field magnetic resonance imaging in patients with rheumatoid arthritis. Mod Rheumatol 2013. DOI:10.1007/s10165-013$0849-4$.

29. Riente L, Delle Sedie A, Filippucci E, et al. Ultrasound imaging for the rheumatologist XXVII. sonographic assessment of the knee in patients with rheumatoid arthritis. Clin Exp Rheumatol 2010; 28: 300-303.

30. Dougados M, Devauchelle-Pensec V, Ferlet JF, et al. The ability of synovitis to predict structural damage in rheumatoid arthritis: a comparative study between clinical examination and ultrasound. Ann Rheum Dis 2013; 72: 665-671.

31. Scirè CA, Iagnocco A, Meenagh G, et al. Ultrasound imaging for the rheumatologist XXXIII. Sonographic assessment of the foot in early arthritis patients. Clin Exp Rheumatol 2011; 29: 465-469.

32. Naredo E, Collado P, Cruz A, et al. Longitudinal power Doppler ultrasonographic assessment of joint inflammatory activity in early rheumatoid arthritis: predictive value in disease activity and radiologic progression. Arthritis Rheum 2007; 57: 116-124.

33. Brown AK, Quinn MA, Karim Z, et al. Presence of significant synovitis in rheumatoid arthritis patients with diseasemodifying antirheumatic drug-induced clinical remission: evidence from an imaging study may explain structural progression. Arthritis Rheum 2006; 54: 3761-3773.

34. Yoshimi R, Hama M, Takase K, et al. Ultrasonography is a potent tool for the prediction of progressive joint destruction during clinical remission of rheumatoid arthritis. Mod Rheumatol 2013; 23: 456-465.

35. Filippucci E, Gabba A, Di Geso L, Girolimetti R, Salaffi F, Grassi W. Hand tendon involvement in rheumatoid arthritis: an ultrasound study. Semin Arthritis Rheum 2012; 41: $752-760$

36. Alcalde M, D'Agostino MA, Bruyn GA, et al. A systematic literature review of US definitions, scoring systems and validity according to the OMERACT filter for tendon lesion in RA and other inflammatory joint diseases. Rheumatology 2012; 51: 1246-1260.

37. Bruyn GAW, Möller I, Bong D, et al. Reliability testing of tendon disease using two different scanning methods in patients with rheumatoid arthritis. First step towards an ultrasonography scoring index. Rheumatology 2012; 51: 16551661.

38. Jaganathan S, Goyal A, Gadodia A, Rastogi S, Mittal R, Gamanagatti S. Spectrum of synovial pathologies: a pictorial assay. Curr Probl Diagn Radiol 2012; 41: 30-42. 
39. Stegbauer J, Rump LC, Weiner SM. Sites of inflammation in painful rheumatoid shoulder assessed by musculoskeletal ultrasound and power Doppler sonography. Rheumatol Int 2008; 28: 459-465.

40. Koski JM. Ultrasound detection of plantar bursitis of the forefoot in patients with early rheumatoid arthritis. J Rheumatol 1998; 25: 229-230.

41. Alasaarela EM, Alasaarela EL. Ultrasound evaluation of painful rheumatoid shoulders. J Rheumatol 1994; 21: 16421648.

42. Coari G, Paoletti F, Iagnocco A. Shoulder involvement in rheumatic diseases. Sonographic Findings. J Rheumatol 1999; 26: 668-673.

43. Iagnocco A, Coari G, Palombi G, Valesini G. Sonography in the study of metatarsalgia. J Rheumatol 2001; 28: 1338 1340.

44. Bowen CJ, Culliford D, Dewbury K, et al. The clinical importance of ultrasound detectable forefoot bursae in rheumatoid arthritis. Rheumatology 2010; 49: 191-192.

45. Gregg JM, Schneider T, Marks P. MR imaging and ultrasound of metatarsalgia: the lesser metatarsals. Radiol Clin North Am 2008; 46: 1061-1078.

46. Bowen CJ, Hooper L, Culliford D, et al. Assessment of the natural history of forefoot bursae using ultrasonography in patients with rheumatoid arthritis: a twelve-month investigation. Arthritis Care Res 2010; 62: 1756-1762.

47. Jin W, Lee JH, Yang DM, et al. Olecranon bursitis communicating with an olecranon cyst in rheumatoid arthritis. J Ultrasound Med 2007; 26: 857-861.

48. Baillet A, Gaujoux-Viala C, Mouterde G, et al. Comparison of the efficacy of sonography, magnetic resonance imaging and conventional radiography for the detection of bone erosions in rheumatoid arthritis patients: a systematic review and meta-analysis. Rheumatology 2011; 50: 1137-1147.

49. Backhaus M, Kamradt T, Sandrock D, et al. Arthritis of the finger joints: A comprehensive approach comparing conventional radiography, scintigraphy, ultrasound, and contrast-enhanced magnetic resonance imaging. Arthritis Rheum 1999; 42: 1232-1245.

50. Szkudlarek M, Narvestad E, Klarlund M, Court-Payen M, Thomsen HS, Østergaard M. Ultrasonography of the metatarsophalangeal joints in rheumatoid arthritis: comparison with magnetic resonance imaging, conventional radiography, and clinical examination. Arthritis Rheum 2004; 50: 2103-2112.

51. Szkudlarek M, Klarlund M, Narvestad E, et al. Ultrasonography of the metacarpophalangeal and proximal interphalangeal joints in rheumatoid arthritis: A comparison with magnetic resonance imaging, conventional radiography and clinical examination. Arthritis Res Ther 2006; 8: R52.

52. Bajaj S, Lopez-Ben R, Oster R, Alarcón GS. Ultrasound detects rapid progression of erosive disease in early rheumatoid arthritis: a prospective longitudinal study. Skeletal Radiol 2007; 36: 123-128.

53. Backhaus M, Burmester GR, Sandrock D, et al. Prospective two year follow up study comparing novel and conven- tional imaging procedures in patients with arthritic finger joints. Ann Rheum Dis 2002; 61: 895-904.

54. Scheel AK, Hermann KG, Ohrndorf S, et al. Prospective 7 year follow up imaging study comparing radiography, ultrasonography, and magnetic resonance imaging in rheumatoid arthritis finger joints. Ann Rheum Dis 2006; 65: 595600.

55. Lopez-Ben R, Bernreuter WK, Moreland LW, Alarcon GS. Ultrasound detection of bone erosions in rheumatoid arthritis: a comparison to routine radiographs of the hands and feet. Skeletal Radiol 2004; 33: 80-84.

56. Disler DG, Raymond E, May DA, Wayne JS, McCauley TR. Articular cartilage defects: in vitro evaluation of accuracy and inter-observer reliability for detection and grading with US. Radiology 2000; 215: 846-851.

57. Möller B, Bonel H, Rotzetter M, Villiger PM, Ziswiler HR. Measuring finger joint cartilage by ultrasound as a promising alternative to conventional radiograph imaging. Arthritis Rheum 2009; 61: 435-41.

58. Filippucci E, Da Luz KR, Di GL, et al. Inter-observer reliability of ultrasonography in the assessment of cartilage damage in rheumatoid arthritis. Ann Rheum Dis 2010; 69: 1845-1848.

59. Jain A, Nanchahal J, Troeberg L, Green P, Brennan F. Production of cytokines, vascular endothelial growth factor, matrix metalloproteinases, and tissue inhibitor of metalloproteinases by tenosynovium demonstrates its potential for tendon destruction in rheumatoid arthritis. Arthritis Rheum 2001; 44: 1754-1760.

60. Grassi W, Filippucci E, Farina A, Cervini C. Sonographic imaging of tendons. Arthritis Rheum 2000; 43: 969-976.

61. Swen WA, Jacobs JW, Hubach PC, Klasens JH, Algra PR, Bijlsma JW. Comparison of sonography and magnetic resonance imaging for the diagnosis of partial tears of finger extensor tendons in rheumatoid arthritis. Rheumatology 2000; 39: $55-62$.

62. Hoving JL, Buchbinder R, Hall S, et al. A comparison of magnetic resonance imaging, sonography, and radiography of the hand in patients with early rheumatoid arthritis. J Rheumatol 2004; 31: 663-675.

63. Wakefield RJ, O'Connor PJ, Conaghan PG, et al. Finger tendon disease in untreated early rheumatoid arthritis: a comparison of ultrasound and magnetic resonance imaging. Arthritis Rheum 2007; 57: 1158-1164.

64. Scheel AK, Schmidt WA, Hermann KG, et al. Inter-observer reliability of rheumatologist performing musculoskeletal ultrasonography: results from a EULAR 'Train the Trainer' course. Ann Rheum Dis 2005; 64: 1043-1049.

65. Naredo E, Möller I, Moragues C, et al. Inter-observer reliability in musculoskeletal ultrasonography: results from a 'Teach-the-Teachers' rheumatologist course. Ann Rheum Dis 2006; 65: 14-19.

66. Baan H, Drossaers-Bakkers WK, Dubbeldam R, Buurke JJ, Nene A, van de Laar MA. Flexor hallucis longus tendon rupture in RA-patients is associated with MTP 1 damage and pes planus. BMC Musculoskelet Disord 2007; 8: 110. 
67. Micu MC, Serra S, Fodor D, Crespo M, Naredo E. Interobserver reliability of ultrasound detection of tendon abnormalities at the wrist and ankle in patients with rheumatoid arthritis. Rheumatology 2011; 50: 1120-1124.

68. Schmidt WA. Value of sonography in diagnosis of rheumatoid arthritis. Lancet 2001; 357: 1056-1057.

69. Lillegraven S, Bøyesen P, Hammer HB, et al. Tenosynovitis of the extensor carpi ulnaris tendon predicts erosive progression in early rheumatoid arthritis. Ann Rheum Dis 2011; 70: 2049-2050.

70. Filippucci E, Iagnocco A, Meenagh G, et al. Ultrasound imaging for the rheumatologist VII. Ultrasound imaging in rheumatoid arthritis. Clin Exp Rheumatol 2007; 25: 5-10.

71. Hau M, Kneitz C, Tony HP, Keberle M, Jahns R, Jenett M. High resolution ultrasound detects a decrease in pannus vascularisation of small finger joints in patients with rheumatoid arthritis receiving treatment with soluble tumour necrosis factor alpha receptor (etanercept). Ann Rheum Dis 2002; 61: 55-58.

72. Iagnocco A, Perella C, Ceccarelli F, et al. Ultrasonographic assessment of the response to Etanercept treatment in patients with rheumatoid arthritis. Reumatismo 2006; 58: 233-238.

73. Filippucci E, Iagnocco A, Salaffi F, Cerioni A, Valesini G, Grassi W. Power Doppler sonography monitoring of synovial perfusion at the wrist joints in patients with rheumatoid arthritis treated with adalimumab. Ann Rheum Dis 2006; 65: 1433-1437.

74. Iagnocco A, Perella C, Naredo E, et al. Etanercept in the treatment of rheumatoid arthritis: clinical follow-up over one year by ultrasonography. Clin Rheumatol 2008; 27 : 491-496.

75. Haavardsholm EA, Østergaard M, Hammer HB, et al. Monitoring anti-TNFalpha treatment in rheumatoid arthritis: responsiveness of magnetic resonance imaging and ultrasonography of the dominant wrist joint compared with conventional measures of disease activity and structural damage. Ann Rheum Dis 2009; 68: 1572-1579.

76. Dougados M, Jousse-Joulin S, Mistretta F, et al. Evaluation of several ultrasonography scoring systems for synovitis and comparison to clinical examination: results from a prospective multicentre study of rheumatoid arthritis. Ann Rheum Dis 2010; 69: 828-833.

77. Hammer HB, Sveinsson M, Kongtorp AK, Kvien TK. A 78-joints ultrasonographic assessment is associated with clinical assessments and is highly responsive to improvement in a longitudinal study of patients with rheumatoid arthritis starting adalimumab treatment. Ann Rheum Dis 2010; 69: 1349-1350.

78. Sibbitt WL Jr, Peisajovich A, Michael AA, et al. Does sonographic needle guidance affect the clinical outcome of intra-articular injections? J Rheumatol 2009; 36: 1892-1902.

79. Sibbitt Jr WL, Band PA, Chavez-Chiang NR, Delea SL, Norton HE, Bankhurst AD. A randomized controlled trial of the cost-effectiveness of ultrasound-guided intra-articular injection of inflammatory arthritis. J Rheumatol 2011; 38: 252-263.
80. Iagnocco A, Cerioni A, Coari G, Ossandon A, Masciangelo R, Valesini G. Intra-articular methotrexate in the treatment of rheumatoid arthritis and psoriatic arthritis: a clinical and sonographic study. Clin Rheumatol 2006; 25 : 159-163.

81. Conti F, Ceccarelli F, Priori R, Iagnocco A, Signore A, Valesini G. Intra-articular infliximab in patients with rheumatoid arthritis and psoriatic arthritis with monoarthritis resistant to local glucocorticoids. Clinical efficacy extended to patients on systemic anti-tumour necrosis factor alpha. Ann Rheum Dis 2008; 67: 1787-1790.

82. Scirè CA, Meenagh G, Filippucci E, et al. Ultrasound imaging for the rheumatologist. XXI. Role of ultrasound imaging in early arthritis. Clin Exp Rheumatol 2009; 27: 391394.

83. Karim Z, Wakefield RJ, Quinn M, et al. Validation and reproducibility of ultrasonography in the detection of synovitis in the knee: a comparison with arthroscopy and clinical examination. Arthritis Rheum 2004; 50: 387-394.

84. Freeston JE, Wakefield RJ, Conaghan PG, Hensor EM, Stewart SP, Emery P. A diagnostic algorithm for persistence of very early inflammatory arthritis: the utility of power Doppler ultrasound when added to conventional assessment tools. Ann Rheum Dis 2010; 69: 417-479.

85. Szkudlarek M, Wakefield RJ, Backhaus M, Terslev L. The discriminatory capacity of ultrasound in rheumatoid arthritis: active vs inactive, early vs advanced, and more. Rheumatology 2012; 51Suppl 7: vii6-9.

86. Genc H, Cakit BD, Tuncbilek I, Erdem HR. Ultrasonographic evaluation of tendons and enthesal sites in rheumatoid arthritis: comparison with ankylosing spondylitis and healthy subjects. Clin Rheumatol 2005; 24: 272-277.

87. Scirè CA, Montecucco C, Codullo V, Epis O, Todoerti M, Caporali R. Ultrasonographic evaluation of joint involvement in early rheumatoid arthritis in clinical remission: Power Doppler signal predicts short-term relapse. Rheumatology 2009; 48: 1092-1097.

88. Filer A, de Pablo P, Allen G, et al. Utility of ultrasound joint counts in the prediction of rheumatoid arthritis in patients with very early synovitis. Ann Rheum Dis 2011; 70: 500507.

89. Ramos PC, Ceccarelli F, Jousse-Joulin S. Role of ultrasound in the assessment of juvenile idiopathic arthritis. Rheumatology 2012; 51Suppl 7: vii10-12.

90. Watanabe T, Takemura M, Sato M, et al. Quantitative analysis of vascularization in the finger joints in patients with rheumatoid arthritis using three-dimensional volumetric ultrasonography with power Doppler. Clin Rheumatol 2012; 31: 299-307.

91. Iagnocco A, Perella C, D'Agostino MA, Sabatini E, Valesini G, Conaghan PG. Magnetic resonance and ultrasonography real-time fusion imaging of the hand and wrist in osteoarthritis and rheumatoid arthritis Rheumatology 2011; 50: 1409-1413.

92. Rednic N, Tămaş MM, Rednic S. Contrast-enhanced ultrasonography in inflammatory arthritis. Med Ultrason 2011; 13: 220-227. 
93. Hammer HB, Fagerhol MK, Wien TN, Kvien TK. The soluble biomarker calprotectin (an S100 protein) is associated to ultrasonographic synovitis scores and is sensitive to change in patients with rheumatoid arthritis treated with adalimumab. Arthritis Res Ther 2011; 13: R178.
94. Ceccarelli F, Perricone C, Fabris M, et al. Transforming growth factor $\beta 869 \mathrm{C} / \mathrm{T}$ and interleukin $6-174 \mathrm{G} / \mathrm{C}$ polymorphisms relate to the severity and progression of boneerosive damage detected by ultrasound in rheumatoid arthritis. Arthritis Res Ther 2011; 13: R111. 